\title{
Die Bestimmung des Thalliums als saures und als neutrales Sulfat.
}

\author{
Von
}

Philip E. Browning. ${ }^{1}$

Crookrs $^{2}$ hat gezeigt, dafs das Salz, welches man erhält, wenn man Thalliumchlorür mit Schwefelsäure erhitzt, bis der Überschuls der letzteren vertrieben ist, und dann die Temperatur auf Rotglut steigert, die Zusammensetzung des neutralen Sulfates besitzt.

Er fand auch, dals beim fortgesetzten Erhitzen kein wesentlicher Gewichtsverlust stattfindet, und er schlug deswegen diese Methode zur Bestimmung des Thalliums vor.

Castangen ${ }^{3}$, der in einer neueren Arbeit die Verbindungen des Thalliums sorgfältig durchforscht hat, bestätigte im wesentlichen Своокеs' Beobachtungen über das neutrale Sulfat, er fügte jedoch noch hinzu, dals dieser Körper bei starkem Erhitzen an der Luft Neigung zur Abgabe von Schwefelsäure zeigt. In der gleichen Arbeit erwähnte er das saure Sulfat und konstatierte, dals dieses beim Erhitzen zuerst schmilzt, dann beim weiteren Erhitzen Schwefelsäure abgiebt und schliefslich neutrales Sulfat hinterlälst.

Die vorliegende Untersuchung wurde nun unternommen, um festzustellen, unter welchen Bedingungen man die beiden genannten Körper zur quantitativen Bestimmung des Thalliums verwenden könnte.

Zur Ausführung dieser Versuche wurde zunächst eine passende Lösung durch Auflösen einer bestimmten Menge Thallonitrat zu einem Liter hergestellt. Der Gehalt derselben wurde durch Fällen gemessener und gewogener Mengen mit Jodid und mit Chromat,

1 Ins Deutsche übertragen von J. KopPex.

2 Chem. News 8, 243.

3 Journ. pr. Chem. 102, 131. 
wie in einer früheren Mitteilung beschrieben, festgestellt. ${ }^{1}$ Nach beiden Methoden gut übereinstimmende Werte wurden als Titer der Lösung angenommen.

Für die Versuche über das Sulfat wurden aus einer Bürette bestimmte Mengen der Lösung in einen gewogenen Platintiegel abgemessen und dann wurde noch das Gewicht der Lösung bestimmt, um eine Kontrolle für die Ablesungen an der Bürette zu haben. Den Inhalt des Tiegels versetzte man mit einigen Tropfen Schwefelsäure und verdampfte dann die Lösung auf dem Wasserbade zur Trockne. Hierauf wurde der Tiegel auf einen „Radiator", der aus einem konischen Eisengefäls bestand, gebracht und auf $220^{\circ}$ bis $240^{\circ} \mathrm{C}$. erhitzt, bis keine Dämpfe mehr entwichen und das Gewicht nach halbstündigem Erhitzen konstant blieb. Die Tiegel wurden in dem Radiator auf einem Thondreieck so aufgestellt, dafs sie ca. $5 \mathrm{ccm}$ von dem auf Rotglut erhitzten Boden desselben entfernt waren. Ein Thermometer, welches so aufgehängt war, dals die Kugel desselben ungefähr ebenso stark erhitzt wurde wie der Tiegel, zeigte die oben angegebene Temperatur an.

Wie aus der folgenden Tabelle hervorgeht, stimmten die auf diese Weise erhaltenen Resultate gut mit den für "saures Sulfat" berechneten Werten überein. Bei verschiedenen Versuchen wurde auch der Rückstand in Wasser gelöst und die Schwefelsäure in demselben durch Fällung mit Bariumnitrat bestimmt. Die so erhaltenen Werte stimmten gut mit den aus der Formel des sauren Sulfates berechneten überein.

\begin{tabular}{c|c|c|c|c|c|c}
\hline \hline & $\begin{array}{c}\text { TlHSO }_{4}, \\
\text { berechnet } \\
\mathrm{g}\end{array}$ & $\begin{array}{c}\mathrm{TlHSO}_{4}, \\
\text { gefunden } \\
\mathrm{g}\end{array}$ & $\begin{array}{c}\text { Fehler } \\
\mathrm{g}\end{array}$ & $\begin{array}{c}\mathrm{Tl}_{\mathbf{8}} \mathrm{SO}_{4}, \\
\text { berechnet } \\
\mathrm{g}\end{array}$ & $\begin{array}{c}\mathrm{Tl}_{2} \mathrm{SO}_{4}, \\
\text { gefunden } \\
\mathrm{g}\end{array}$ & $\begin{array}{c}\text { Fehler } \\
\mathrm{g}\end{array}$ \\
\hline \hline & 0.1605 & 0.1596 & $0.0009-$ & 0.1344 & 0.1346 & $0.0002+$ \\
2 & 0.1611 & 0.1608 & $0.0003-$ & 0.1349 & 0.1346 & $0.0003-$ \\
3 & 0.1608 & 0.1608 & $0.0000 \pm$ & 0.1347 & 0.1352 & $00005+$ \\
4 & 0.1612 & 0.1600 & $0.0012-$ & 0.1350 & 0.1346 & $0.0004-$ \\
5 & 0.1602 & 0.1596 & $0.0006-$ & 0.1341 & 0.1346 & $0.0005+$ \\
6 & 0.1608 & 0.1596 & $0.0012-$ & & & \\
7 & 0.1617 & 0.1604 & $0.0013-$ & & & \\
8 & 0.1608 & 0.1592 & $0.0016-$ & 0.1347 & 0.1358 & $0.0011+$ \\
9 & 0.1609 & 0.1590 & $0.0019-$ & 0.1348 & 0.1346 & $0.0002-$ \\
& & & & & &
\end{tabular}

${ }^{1}$ Amer. Journ. Soe. (Sill.) 8, 460. - Z. anorg. Chem. 22, 380. 
Nachdem in der beschriebenen Weise das saure Sulfat bestimmt war, wurden die Tiegel über freier Flamme zur dunklen Rotglut erhitzt; hierbei entwickelten sich wieder starke Schwefelsäuredämpfe, dann aber wurde das Gewicht wieder konstant und die oben verzeichneten Resultate zeigen, dals der Rückstand wirklich aus neutralem Sulfat bestand. Auch bei verschiedenen von diesen Versuchen wurde nochmals die Schwefelsäure bestimmt und es ergab sich stets, dals ihre Menge einem neutralen Sulfat entsprach.

Diese Resultate zeigen, dafs man das Thallium sowohl als saures wie auch als neutrales Sulfat quantitativ bestimmen kann, wenn man sorgfältig die angegebenen Temperaturbedingungen inne hält.

The Kent Chemical Laboratory of Yale University, New Haven, U. S. A.

Bei der Redaktion eingegangen am 1. Dezember 1899. 